\title{
2092 Myocardial field distortions during first pass of a gadolinium based contrast agent in perfusion studies Pedro Ferreira*1, Peter Gatehouse ${ }^{2}$, David Firmin ${ }^{1}$, Chiara Bucciarelli-Ducci ${ }^{1}$ and Ricardo Wage ${ }^{2}$
}

Address: ${ }^{1}$ Imperial College London, London, UK and ${ }^{2}$ Royal Brompton Hospital, London, UK

* Corresponding author

from I th Annual SCMR Scientific Sessions

Los Angeles, CA, USA. I-3 February 2008

Published: 22 October 2008

Journal of Cardiovascular Magnetic Resonance 2008, I0(Suppl I):A36I doi:I0.I I86/I532-429X-I0-SI-A36 I

This abstract is available from: http://jcmr-online.com/content//0/SI/A36I

(c) 2008 Ferreira et al; licensee BioMed Central Ltd.

\section{Background}

Myocardial Perfusion (MP) studies using MRI have lately improved in terms of resolution and coverage, providing a valuable contribution to the detection of Coronary Artery Disease (CAD). However, MP images are often affected by artifacts, most commonly the Dark Rim Artifact (DRA), which appears in the subendocardium during the first left-ventricular pass of the Contrast Agent (CA) mimicking an under-perfused region.

The exact origins of the DRA are unclear and several causes have been suggested: motion [1]; Gibbs truncation [2]; non-uniform k-space weighting [3]; and susceptibility associated with CA concentration [4-6].

\section{Aim}

In this work a method has been developed and used to measure the field distortions caused by the first pass of a CA in a typical perfusion setup, and determine how these distortions may depend on cardiac long-axis orientation.

\section{Methods}

Gd contrast agent (Magnevist-Schering; Germany), with a dose of $0.1 \mathrm{mmol} / \mathrm{kg}$ of body weight was injected at $5 \mathrm{~mL} /$ $s$ in 12 patients (average age 49). Field plots were acquired in three short-axis slices, during the first pass of CA with the patients holding their breath for as long as comfortably possible during $40 \mathrm{R}-\mathrm{R}$ intervals. The study was performed using a $1.5 \mathrm{~T}$ scanner (Avanto; Siemens) with anterior/posterior phased array cardiac coils. A FLASH sequence was used with magnitude and phase reconstructions: TR/TE of 256/2.48 ms; base resolution 192 pixels; pixel size $1.8 \times 1.8 \times 10 \mathrm{~mm}$ to $2.2 \times 2.2 \times 10 \mathrm{~mm}$; flip angle 12 degrees; bandwidth $744 \mathrm{~Hz} /$ pixel; GRAPPA, R = 1.7. The coil images were saved separately, and phase correction was disabled in image reconstruction.

Single-shot frequency-offset maps were calculated using Matlab (Mathworks; US-MA) where the phase image of each coil for the first frame (before CA) was subtracted from each subsequent frame's corresponding phase images, before magnitude-weighted phase combination. The first frame was chosen to be that before contrast arrival to the right ventricle but with the patient at a stable breath-hold position. Four ROIs were drawn in the subendocardium (septal, posterior, lateral, anterior) for each slice (basal, mid, apical), and frequency offsets as a function of time were extracted, measuring also the peak field distortion of each ROI during the contrast agent first pass. The in-vivo measurements were compared with numerical simulations and specially constructed phantoms that mimicked the LV chamber and expected susceptibility differences,

\section{Results and discussion}

First-pass contrast agent in the LV distorts myocardial B0 (Figure 1). The distortion tends to increase when the heart long axis is more across B0 (Figure 2). The in-vivo measurements showed the same pattern, and similar frequency offsets when compared to both numerical simulations 


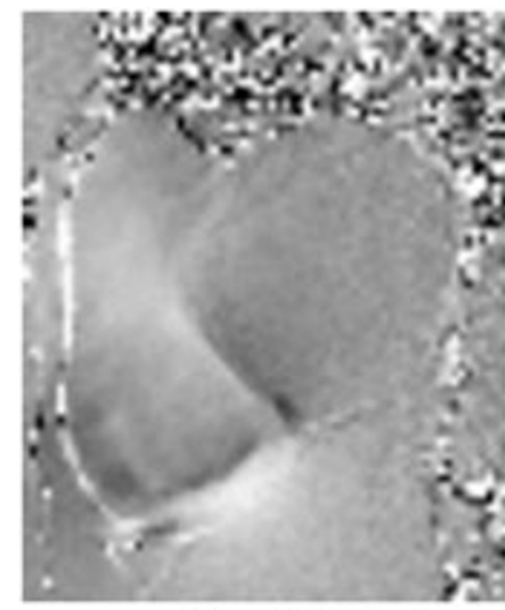

arrival RV

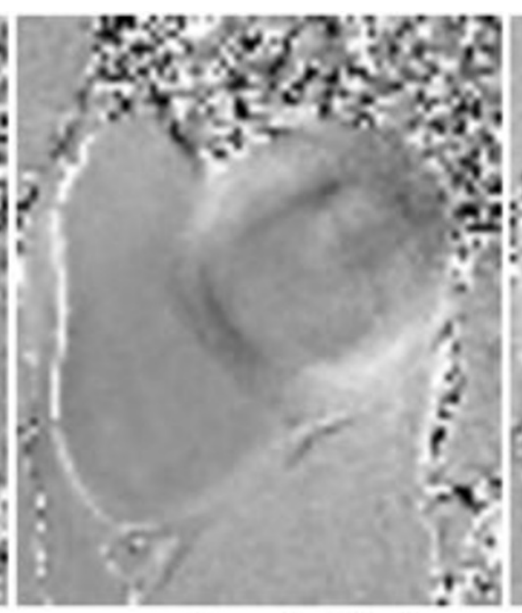

arrival LV

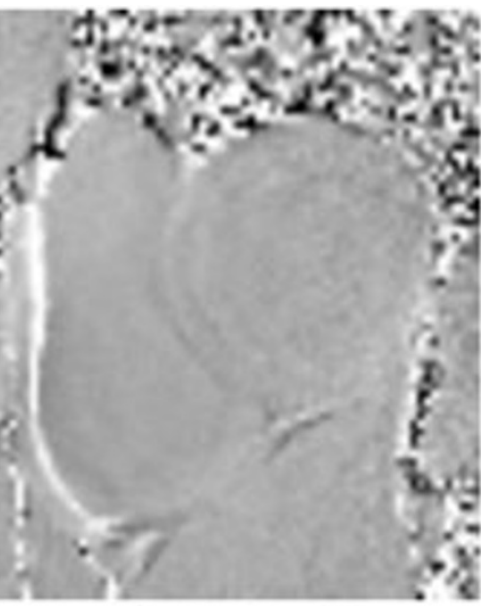

recirculation

\section{Figure I}

Field distortion for the first pass of Gd-DTPA in the heart for one of the patients. From left to right we have the first pass of contrast agents in the right ventricle, the left ventricle and during recirculation. During the first pass in the LV, all patients showed an increase of BO in the posterior and anterior myocardial segments (brighter regions) and a decreasing of B0 in the septal and lateral segments (darker regions). The in plane component of B0 is shown.

and the phantom (Figure 3). The field distortion measured in this study resulted in a maximum frequency shift of $70 \mathrm{~Hz}$ in the subendocardiual region coupled with a $20 \mathrm{~Hz}$ shift in the LV blood-pool. If we consider a perfusion sequence with a TE of $1 \mathrm{~ms}$, this would cause an intra-voxel phase range of approximately 0.57 radians between the subendocardium and the blood-pool. Assuming a worst-case $50 \%$ partial volume with the LV, the voxel's total signal would be reduced by approximately $10 \%$ only.

\section{Conclusion}

During the first-pass, B0 distortion occurs mainly in the subendocardium, and the same pattern is always observed (anterior/posterior positive; septal/lateral negative). The myocardial B0 distortion is larger in patients with a more "horizontal" heart. From these results it would appear that the field distortions are too weak to cause DRAs due to intravoxel dephasing. 

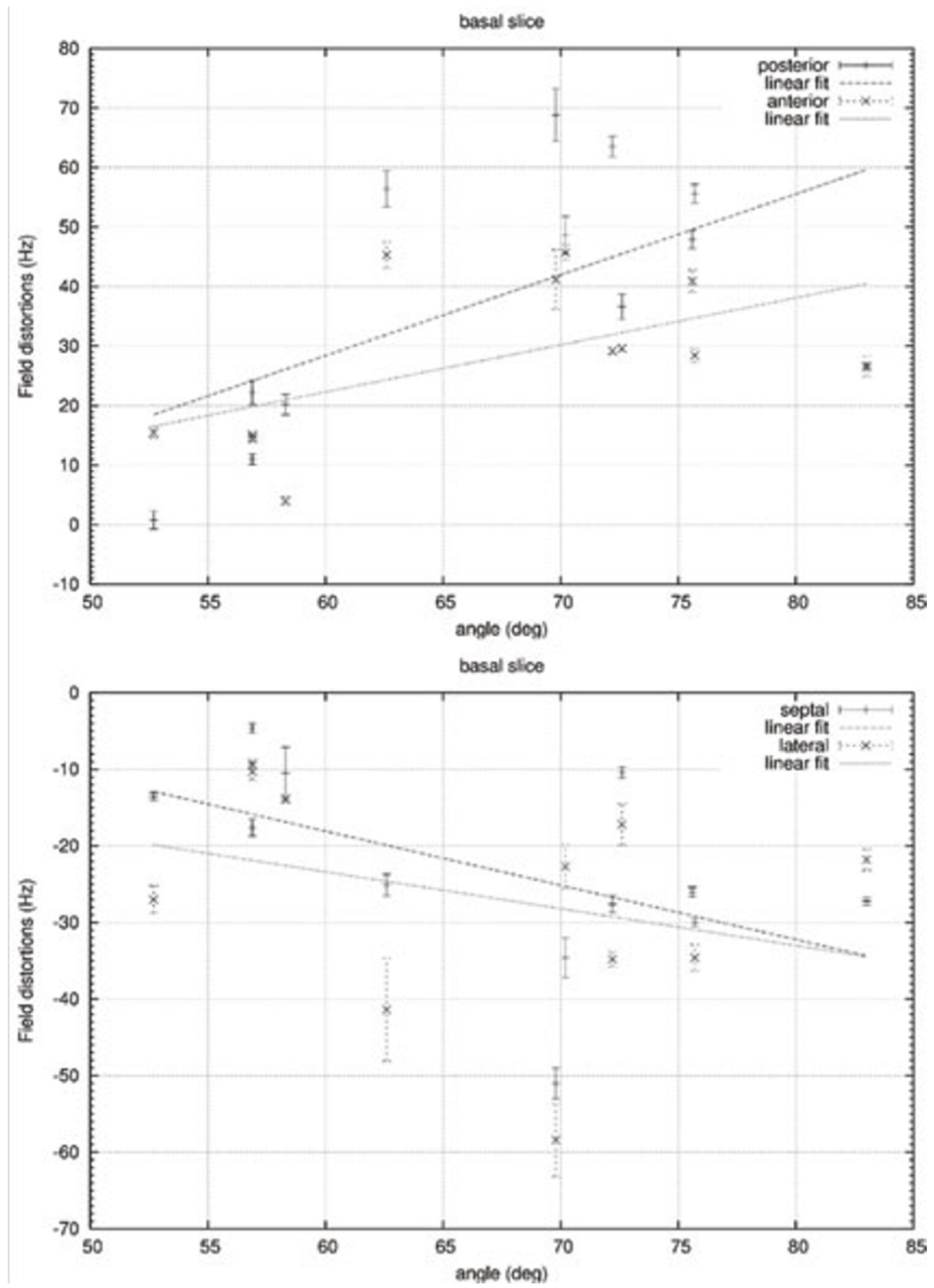

Figure 2

Peak field distortions measured in patients as a function of the angle between the long axis of the heart and B0. The top graph shows measurments for the positive field distortions in the posterior and anterior while the bottom shows the negative phase distortions in the septal and lateral regions of the myocardium. (R-squared: posterior 0.34; anterior 0.30; septal 0.28; lateral $0.10)$. 


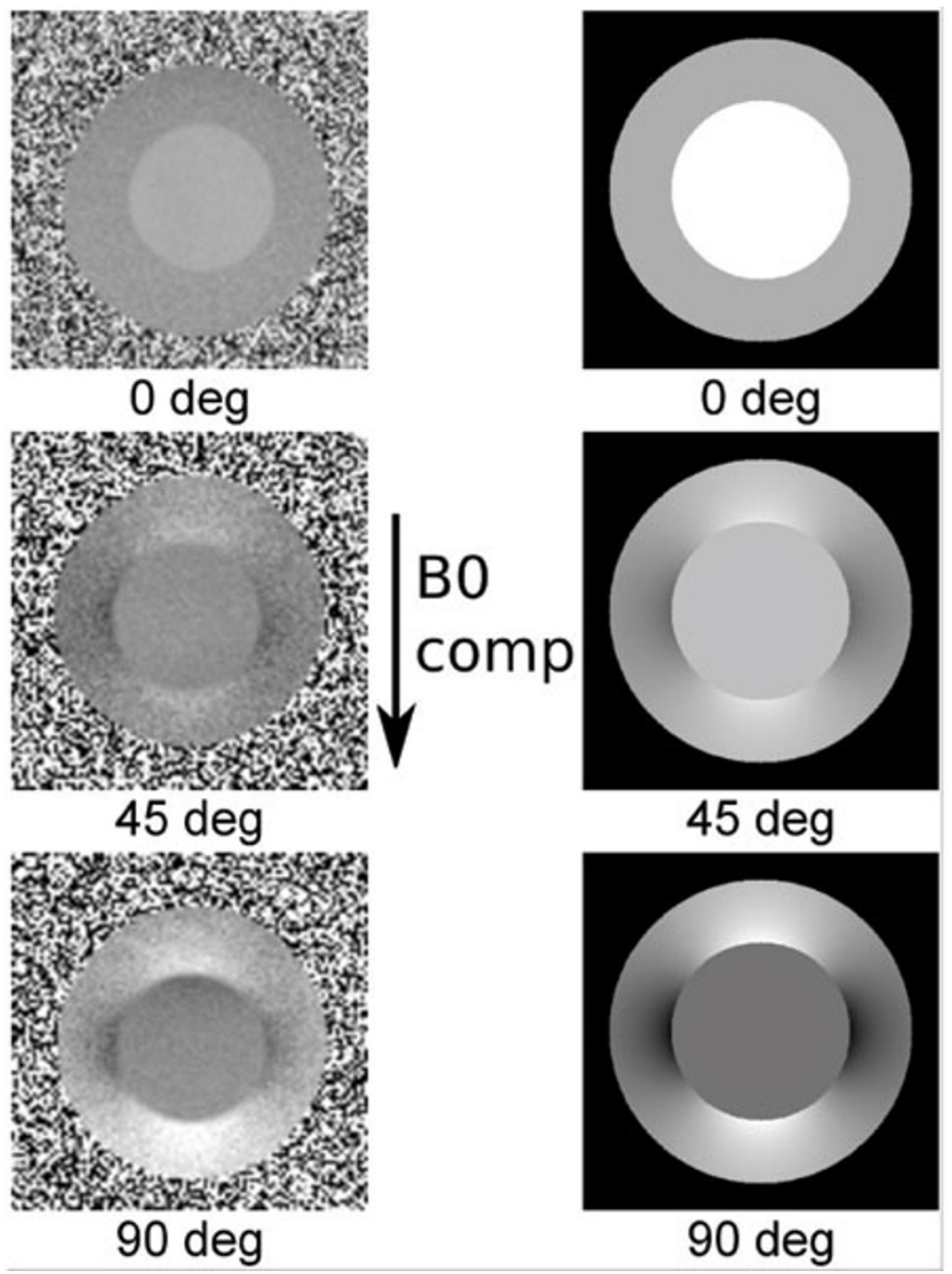

Figure 3

Left: Cylindrical phantom with susceptibilities similar to the ones obtained in the myocardium and left ventricle during the first pass, assuming $1 \%(5 \mathrm{mmol} / \mathrm{L})$ of Gd-DTPA concentration in the LV. The angle shown is between B0 and the orientation of the long axis of the cylinder. When the cylinder lay across B0 (90 deg), corresponding to 'horizontal heart' morphology, phase distortions of around $60 \mathrm{~Hz}$ were measured in the subendocardial regions of the phantom. Right: numerical simulations of B0-field distortion based on the setup of the left. Similar phase distortions were obtained. The plane component of BO is shown.

\section{References}

I. Storey P, et al.: MRM 2002, 48(6): 1028.

2. Di Bella E, et al:: MRM 2005, 54(5): 1295 .

3. Kellman P, Arai A: JCMR 2007, 9(3):525.

4. Arai A: Top MRI 2000, I I (6):383-398.

5. Fenchel Michael, et al.: JMRI 2004, I 9(5):555.

6. Schreiber W, et al.: JMRI 2002, I 6(6):64I.
Publish with Biomed Central and every scientist can read your work free of charge

"BioMed Central will be the most significant development for disseminating the results of biomedical research in our lifetime. "

Sir Paul Nurse, Cancer Research UK

Your research papers will be:

- available free of charge to the entire biomedical community

- peer reviewed and published immediately upon acceptance

- cited in PubMed and archived on PubMed Central

- yours - you keep the copyright
BiolMedcentral 